\title{
Platô Sistêmico na Teoria Social: Uma Revolução Científica às Avessas
}

\author{
Léo Peixoto Rodrigues
}

Universidade Federal de Pelotas (UFPel), Pelotas, Rio Grande do Sul, Brasil. E-mail: leo.peixotto@gmail.com

\section{INTRODUÇÃO}

$\mathrm{O}$ presente artigo tem por objetivo confrontar aspectos de fundamentação epistemológica de duas importantes vertentes teóricas que se desenvolveram, quase que concomitantemente, em termos temporais: o estrutural-funcionalismo, nos Estados Unidos, e o estruturalismo, na França. O motivo desse confronto é ressaltar o fato de que ambas as teorias desenvolvem-se sobre uma mesma base epistemológica sistêmica: uma, oriunda da cibernética; outra, da linguística de Ferdinand de Saussure. A partir da reconstrução de determinados aspectos da história teórica sociológica, logo após a "crise" da sociologia clássica, nas décadas que se seguiram às mortes de Durkheim e de Weber, buscou-se demonstrar as congruências de fundamentação e a plataforma epistemológica que essas correntes utilizam para realizar as (mesmas) pretensões de cientificidade e de metarrelato.

Para tanto, o artigo está estruturado em três partes centrais: a primeira reconstrói, de forma panorâmica, os principais elementos do desenvolvimento da teoria sociológica, tanto nos Estados Unidos como na Europa, durante o período que vai de 1920 a 1945 do século recémpassado. Este esforço é para situar o leitor acerca dos principais conceitos que serão abordados durante o desenvolvimento do trabalho, tais

DADOS - Revista de Ciências Sociais, Rio de Janeiro, vol. 57, n-4, 2014, pp. 1109 a 1135. 
como: função (funcional), estrutura (estrutural) e sistema. Posteriormente, na segunda parte, busca-se demonstrar: a) as bases sistêmicas sobre as quais se desenvolve o estruturalismo francês; e, b) por que essa vertente teórica distancia-se do conceito de sistema, fartamente empregado por Saussure na teoria moderna da linguagem, de onde Lévi-Strauss transporta os fundamentos epistemológicos para fundar o estruturalismo nas ciências sociais, adotando, no lugar do termo "sistema", o termo "estrutura". O mesmo, ainda dentro desta segunda parte, é feito com o conceito de sistema utilizado pelo estruturalfuncionalismo de Talcott Parsons, isto é, embora a teoria de Parsons seja mais conhecida como sistêmica, esse autor empregou durante os anos 1940 os termos "estrutural" e "funcional" para descrever a dinâmica que desejava dar à sua teoria, mas que também poderia ser melhor descrita pelo termo sistema.

Por fim, o artigo adentra em seus argumentos centrais, destacando que a noção de sistema ao longo do século XX, mas principalmente a partir do desenvolvimento destas duas vertentes teóricas em lados distintos do Atlântico, não apenas dá a ambas uma importante congruência de fundamentação: a perspectiva sistêmica, como o próprio termo sistema, pouco a pouco assume um status de teoria sistêmica, robustecendo-se dentro das ciências sociais até os dias de hoje, provocando uma "revolução científica", nos termos propostos por Thomas Kuhn, mas às avessas: através de diferentes processos de síntese, o sistema, a partir da crise do estruturalismo e da teoria parsoniana, robustece-se como possibilidade de fundamentação teórica, por vezes implícita, por vezes explicitamente, sobretudo na produção da teoria sociológica europeia.

\section{UMA MESMA BUSCA POR FUNDAMENTAÇÃO E CIENTIFICIDADE: A SOCIOLOGIA EM LADOS OPOSTOS DO ATLÂNTICO}

Se forem consideradas as principais correntes da teoria sociológica desenvolvida durante o século XX após a "crise da sociologia clássica" do entreguerras, com a morte de Max Weber, em 1920, e a ausência de seguidores da sociologia compreensiva ${ }^{1}$, bem como o declínio do durkheimianismo, iniciado ainda na década de 1930 e aprofundado logo após a II Guerra Mundial, constatar-se-á um esforço da sociologia internacional para se reconstituir (Cuin e Gresle, 1994). Com exceção da sociologia norte-americana, que nas primeiras décadas do século XX já se mostrava pujante, sobretudo com a Escola de Chicago, 
na maior parte do mundo, nas décadas de 1920 a 1950, aproximadamente, a sociologia girava em torno do marxismo de diversas nuances e do funcionalismo, cujo controvertido debate voltou à cena após Durkheim e se estendeu até a década de 1970, quando as controvérsias e avanços pareciam ter se esgotado. Na Inglaterra, depois de Spencer e até a década de 1960, o papel da sociologia nas ciências humanas era exercido pela antropologia, que durante esse tempo lhe roubou a cena intelectual (Giddens, 2001). Na França, além do marxismo francês, o existencialismo humanista de Jean-Paul Sartre - filósofo que se tornou uma estrela não apenas do intelectualismo filosófico francês, mas também pelo seu "engajamento" social - de certo modo satisfaziam, em parte, algumas lacunas da explicação dos fenômenos sociais. Contrariamente aos filósofos clássicos, Sartre afirmava que a existência precedia a essência. Para esse filósofo, o homem é o que ele se faz, evocando, por um lado, a liberdade e, por outro, a contingência (Huisman, 2001). De alguma forma, tais posições filosóficas cumpriam o papel de uma sociologia da ação, cujo caráter humanista abria espaço, ao mesmo tempo, para a liberdade, para indeterminação e para o que se constitui em um dos maiores valores: o humano.

Nos Estados Unidos, a Escola de Chicago, cujo desenvolvimento iniciou-se a partir de 1910, mesmo período do "suave" declínio da sociologia de caráter positivista/evolucionista de influência europeia (Comte e Spencer), focou suas atividades a partir de uma série de pesquisas, cujas vertentes - psicologia social, quantitativismo de caráter censitário, sociologia urbana etc. - apoiavam-se fortemente em trabalhos empíricos - uma empiria relativamente carente de teoria genuinamente sociológica, no sentido (evidente) das abordagens macrossociológicas, clássicas, também de origem europeia. O Interacionismo simbólico, umas das abordagens que se tornaram mais conhecidas internacionalmente, conseguiu, entretanto, formar um corpus teórico mais robusto, porém, ainda aplicado à microssociologia, com importantes traços das abordagens pragmatista e psicológica² ${ }^{\text {(Levine, }}$ 1997).

Entrementes, a sociologia norte-americana desenvolveu outra importante escola, mesmo antes da década de 1930, cujo nascimento não estava vinculado - ou se desvinculara buscando uma trajetória autônoma - à microssociologia e ao pragmatismo da Escola de Chicago. Tratava-se de uma abordagem sistêmica ${ }^{3}$ iniciada, dentre outros pesquisadores menos conhecidos, por Robert M. MacIver, escocês que 
lecionou no Canadá e imigrou para os Estados Unidos em 1927, estando vinculado à Universidade de Columbia até sua aposentadoria; pelo polonês Florian Znaniecki, que migrou para os Estados Unidos durante a Primeira Guerra Mundial; e por Pitirim A. Sorokin, de nacionalidade russa, que após 1919 exilou-se nos Estados Unidos, tornando-se professor da Universidade de Minnesota - e mais tarde fundou o departamento de sociologia da Universidade de Harvard. Este último, mais conhecido em línguas latinas, também foi um marcante expoente dessa Escola Sistêmica Norte-Americana. Estes pesquisadores tiveram alguma influência nos trabalhos de Parsons, mesmo antes de 1937, quando ele publicou sua obra A Estrutura da Ação Social (1968a), que foi o primeiro passo para que se tornasse internacionalmente conhecido. Aliás, essa corrente sistêmica americana passou a ser conhecida, posteriormente, mais pelos trabalhos de Parsons e também pelo nome de estrutural-funcionalismo, embora os demais autores tenham desenvolvido trabalhos de repercussão internacional ${ }^{4}$ (Sorokin, 1971; Timasheff, 1971).

Este breve panorama do estatuto da sociologia em algumas partes do mundo não tem a pretensão de fazer uma história da disciplina do entre e pós-guerras - existe farta e importante bibliografia a respeito ${ }^{5}$. $\mathrm{O}$ intento aqui é destacar de forma simplificada um momento anterior ao surgimento de duas importantes vertentes de pensamento teórico, uma nos Estados Unidos, e outra do outro lado do Atlântico, na França: o pensamento sistêmico e o pensamento estruturalista. Estas correntes, se é que se pode referir dessa forma, parecem ter surgido de modo completamente diferenciado e sem qualquer ponto de toque epistemológico, teórico, ou metodológico. Entretanto, não foi bem assim ${ }^{6}$.

Essas duas abordagens teóricas frequentemente são estudadas e discutidas como se não apresentassem qualquer semelhança de fundamentação, epistemológica, teórica ou mesmo metodológica. Todavia, como será possível constatar, tais abordagens, a sistêmica e a estruturalista, guardam mais semelhanças que diferenças, e a exploração dessas semelhanças pode ser útil não apenas como um resgate histórico, mas também de elementos para o próprio avanço da teoria contemporânea. É necessário advertir, porém, que não é intenção deste artigo explicar em detalhes ambas as teorias e seus meandros conceituais, objeto de riquíssimos debates ao longo dos últimos 50 anos principalmente. Para a consecução do objetivo a que se propõe este artigo, buscar-se-á demonstrar as congruências a partir de eixos epistemológicos, ou seja, do 
substrato comum - ou pelo menos comensurável - que dá sustentação a ambas reflexões teóricas: ao pensamento sistêmico norte-americano surgido durante a década de 1940 e, igualmente, ao estruturalismo, cuja a gênese também se encontra na mesma década quando da passagem de Lévi-Strauss por Nova York. Em outro lugar, afirmou-se que:

Em 1941 Lévi-Strauss viaja para Nova York para lecionar na "New School for Social Research", conhecendo e se tornando amigo do linguista Roman Jakobson, participando, inclusive de seus cursos sobre linguística. É a partir de então que Lévi-Strauss percebe a potencialidade da linguística para se pensar os distintos fenômenos culturais (Rodrigues, 2010:141).

Embora a noção de sistema - da mesma forma que a noção de estrutura - tenha sido utilizada desde os primórdios da teoria sociológica e não somente nela, mas principalmente na filosofia (sistema kantiano, sistema hegeliano etc.), o uso que se fazia não encerrava uma maior reflexão sobre estes termos. Eles eram utilizados, sistema e estrutura, muitas vezes como sinônimos, para designar um todo formado por partes articuladas ou não; quando se queria dar mais mobilidade a esse todo, falava-se em sistema, quando se pretendia ressaltar aspectos mais estáticos falava-se em estruturas (Rodrigues, 2006).

Se a noção de sistema, na sociologia contemporânea, invade a academia de forma interdisciplinar, sobretudo a partir das Conferências de $\mathrm{Macy}^{7}$, que acolheu uma importante gama de pesquisadores ciberneticistas, o estruturalismo francês tem o seu nascimento a partir da linguística moderna espalhando-se interdisciplinarmente. Assim, como um resumo esquemático do que foi dito até então, vejamos o Esquema 1 a seguir.

Após a apresentação do Esquema 1, além das notas que lhes foram agregadas, cabem ainda algumas considerações, dada a "simplicidade" com que parte importante da teoria sociológica foi nele apresentada. Intencionou-se centralmente, com o esquema, a partir da "crise" dos clássicos nas primeiras décadas do século XX, salientar os caminhos que as sociologias norte-americana e francesa "coincidentemente" seguiram durante os anos 1940. Ambas as teorias tinham duas (e as mesmas) ambições: por um lado, construírem um estatuto de cientificidade e, por outro, não se constituírem em sociologias puramente da ação, mas que essa fosse envolvida ou subordinada (dada a sua dimensão de subjetividade) por uma dimensão estrutural, sistêmica. 


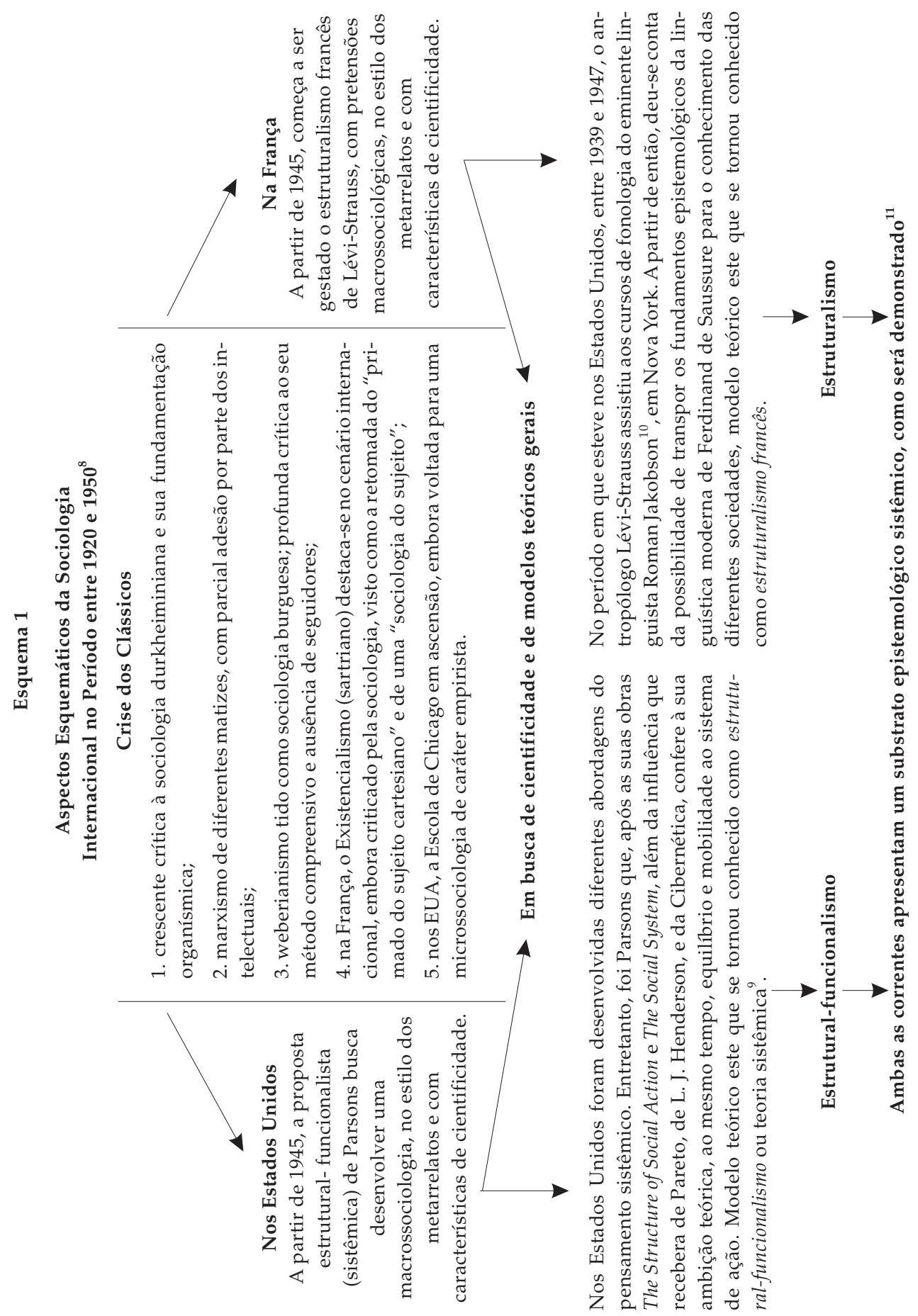

1114 DADOS - Revista de Ciências Sociais, Rio de Janeiro, vol. 57, no 4, 2014 
No caso da sociologia americana, a proposta estrutural-funcionalista ou sistêmica de Talcott Parsons deixa evidente tal ambição na seguinte passagem: "O ponto de partida fundamental é o conceito de sistema social de ação. (...) A interação dos atores individuais está posta em condições tais que é possível considerar este processo de interação um sistema (no sentido científico) e submetê-lo às mesmas ordens de análise teóricas que têm sido aplicadas com êxito a outros tipos de sistemas em outras ciências" (1966:23; ênfases minhas). Já no caso da sociologia francesa, a "descoberta" de Lévi-Strauss das estruturas "ausentes" da linguística moderna, que via a língua como um sistema e os atos de fala como sobredeterminados pelas regras não aparentes da língua, fê-lo acreditar que as diferentes sociedades eram sobredeterminadas por estruturas (inconscientes) que atuavam sobre as ações de seus membros. A passagem a seguir é elucidativa:

Ela [o nascimento da fonologia] não renovou apenas as perspectivas linguísticas uma transformação de tal amplitude não se limita a uma disciplina específica. A fonologia desempenha, em relação às ciências sociais, o papel renovador que a física nuclear, por exemplo, desempenhou para com o conjunto das ciências exatas. (...) finalmente, ela visa à descoberta de leis gerais, descobertas ou por indução, ou deduzidas logicamente, o que lhes dá um caráter absoluto (Lévi-Strauss, 2003:60).

Ao abordar este período da teoria sociológica, intencionalmente não se buscou discutir os meandros do rico e importante debate havido principalmente sobre a Escola Funcionalista que envolveu esforços teóricos tanto europeus como americanos; tampouco se debateu a também importante discussão sobre os problemas epistemológicos e metodológicos das ciências sociais, em geral, e da sociologia em específico, que, inclusive, deram origem à sociologia do conhecimento e a uma gama de textos sobre métodos ${ }^{12}$. $\mathrm{O}$ foco que se buscou foi justamente o de mostrar que os esforços teóricos de cientificidade de uma macrossociologia conduziram a duas vertentes, a estrutural-funcionalista e a estruturalista, aparentemente incomunicáveis (e incomensuráveis) com relação ao mesmo substrato epistêmico, ou seja: uma perspectiva epistemológica sistêmica do social, ponto este que será discutido detalhadamente a seguir e que se constitui, acredita-se, na principal contribuição deste artigo. Antes, porém, a perspectiva apresentada por Losano no que se refere a essa mútua "cooperação silenciosa" do estruturalismo e do pensamento sistêmico é especialmente relevante quando destaca que: 
(...) também na Europa havia uma expectativa por essa mudança de paradigma, mas sua realização fora retardada pelas ditaduras e pela guerra. $\mathrm{O}$ advento das teorias sistêmicas nos Estados Unidos do pós-guerra ajuda a compreender melhor o sucesso do estruturalismo europeu, uma vez que ambos são manifestações históricas, específicas da mesma exigência científica geral (Losano, 2011:230-231).

\section{ESTRUTURALISMO E ESTRUTURAL FUNCIONALISMO: UMA MESMA PLATAFORMA COGNITIVA SISTÊMICA}

\section{A Fundamentação Sistêmica do Estruturalismo Francês}

Quando o estruturalismo transpõe a fundamentação epistemológica oriunda da linguística moderna para o estudo das sociedades, o termo estruturalismo já existia na linguística há aproximadamente duas décadas. "Foi o linguista dinamarquês Louis Hjelmslev quem reivindicou o emprego do termo estruturalismo, derivando-o da já conhecida palavra estrutura, como fundamento epistemológico e método de abordagem científica. (...) Hjelmslev fundou, em 1939, a revista Acta Linguística, em que constava um primeiro artigo referindo-se à linguística estrutural" (Rodrigues, 2006:35-67). Na antropologia, o termo foi utilizado justamente para se diferenciar das clássicas utilizações dos termos estrutura e estrutural; o sufixo "ismo" também atenderia às pretensões lévi-straussianas: status de escola ${ }^{13}$, corrente, ou mesmo movimento, além do caráter cientificista.

Conceitos são constantemente ressemantizados, seja para conotar detalhes diferenciais do pensamento, seja para aderir ao mainstream de uma determinada época. Nesse caso, a noção de estrutura, que sobreviveu ao declínio da teoria clássica, estava sendo utilizada como uma "âncora" conceitual para a descrição de múltiplos fenômenos teóricos, em quase todas as abordagens sociológicas ${ }^{14}$. Nesse sentido, a adoção do termo estruturalismo, pela antropologia, para a investigação de fenômenos sociais, não apenas vinha ao encontro do conceito que estava em voga no momento como também lhe conferia uma nova roupagem. Como Lévi-Strauss estava levando uma importante novidade para a Franca ao final da década de 1940, convicto de que os mesmos fundamentos da linguística moderna apresentavam capacidade explicativa revolucionária para o entendimento científico do fenômeno social, nada mais lógico do que "reembalar" o conceito estrutural da mesma forma que havia sido feito na linguística moderna. Daí a emergência 
do estruturalismo francês, que se diferenciava de todas as abordagens estruturais, cuja fundamentação epistemológica originava-se de uma perspectiva organísmica, biologista, da qual, sobretudo os franceses, queriam se afastar. Como já foi mencionado em outro lugar:

(...) foi de fato Claude Lévi-Strauss quem teve o mérito de transpor, da linguística moderna para as ciências sociais, a fundamentação epistemológica que caracterizou o estruturalismo como tal (...) Quando falamos em transposição dos fundamentos epistemológicos da linguística (...) referimo-nos à "descoberta" de estruturas inteligíveis subjacentes a diferentes objetos (objetos, esses, geralmente vinculados à atividade humana), para além de sua aparente organização, que consigam explicá-los de forma mais profunda, de modo mais cabal. Esse primeiro esforço de definição do estruturalismo demonstra, desde logo, o quanto essa noção está vinculada à linguística moderna. Essa é sem dúvida a importante inovação que Lévi-Strauss deu à antropologia francesa, retirando-a da sua filiação às ciências da natureza (Rodrigues, 2010:139-140).

Sem a intenção de discutir-se aqui o estruturalismo francês, cuja bibliografia é abundante e profunda ${ }^{15}$, objetiva-se, pontualmente, aclarar que o nome "estruturalismo", dado a este movimento teórico desenvolvido genuinamente na França, não corresponde necessariamente àquilo que a noção de estrutura, nem tradicionalmente, nem contemporaneamente, denota. Isto porque a noção de estrutura, estrutural ou mesmo estruturalismo, para refletir a dimensão de fundamentação da proposta teórica saussuriana, é meramente conotativa com relação ao seu pensamento. Em outros termos, toda a estrutura teórica e de fundamentação - por isto epistemológica - da linguística moderna proposta de forma tão bem acabada por Ferdinand de Saussure é melhor denotada, explicada pelo conceito de sistema. Aliás, Saussure nunca utilizou o termo estrutura para se referir às questões centrais da linguística moderna, nos cursos de Linguística Geral que ministrou durante o período de 1906 a 1911, na Universidade de Genebra ${ }^{16}$. O termo que sempre foi empregado por Saussure e seus discípulos foi de fato sistema: "A palavra 'estrutura' não chega a ser mencionada explicitamente no Curso, mas a noção de 'sistema', largamente empregada, contém implícito o mesmo significado quando Saussure define 'língua' como 'um sistema cujos termos são todos solidários e em que 'o valor de um não resulta senão da presença simultânea dos outros'" (Benveniste, 1978:VII). O termo sistema, utilizado por Lévi-Strauss em muitas das vezes como si- 
nônimo de estrutura, evidentemente foi necessário para comunicar a ideia de mobilidade relacional, interdependência das partes, interação e integração, movimentos estes muito bem caracterizados na linguística saussuriana, sobretudo no seu nível de sincronicidade.

Destarte, é importante que se frise o fato curioso e pouco mencionado na literatura estruturalista: se por um lado a linguística moderna de Saussure foi fundamental para o desenvolvimento do estruturalismo francês, por outro, os termos estrutura e estruturalismo, já em uso por Lévi-Strauss e pelas adesões teóricas que se seguiram durante as décadas de 1950 e 1960, dado o caráter interdisciplinar que assumiu esse movimento, passaram a ser incorporados pelos linguistas modernos no lugar do termo sistema, originalmente utilizado por Ferdinand de Saussure e seus discípulos. A passagem a seguir, escrita por Émile Benveniste $^{17}$, é particularmente elucidativa:

O termo [estrutura] tornou-se tão difundido que os pesquisadores o empregam em diferentes acepções (...) Em alguns casos, "estrutura" é entendida como um "sistema que explica o arranjo do todo em partes, as quais são solidárias"; em outros casos, fala-se de "estrutura" como "disposição, num todo organizado, dos elementos das substâncias concretas". Mas apesar da diversidade de conceituações, é inegável que desde a década de 1940, o estruturalismo foi o movimento que mais se impôs à atenção dos especialistas tornando-se o motor ativo da Linguística (1978:VII; ênfases minhas).

Os estruturalistas, por diversas vezes, necessitaram recorrer à noção de sistema para que pudessem ser melhor compreendidos. A antropologia estruturalista também se utiliza da noção de sistema de forma implícita o tempo todo, e em diversos casos, de forma explícita. Na obra de Lévi-Strauss, Antropologia Estrutural (2003), tida como um dos grandes marcos do estruturalismo, as passagens em que o autor usa o termo sistema são inúmeras como a que segue, por exemplo:

No estudo dos problemas de parentesco (e certamente também no estudo de outros problemas), os sociólogos se veem numa situação formalmente análoga à dos linguistas fonólogos: como os fonemas, os termos de parentesco são elementos de significação; como eles, só adquirem essa significação se integrados em sistemas; os "sistemas de parentesco", assim como os "sistemas fonológicos", são elaborados pelo espírito no estágio do pensamento inconsciente... (Lévi-Strauss, 2003:61; ênfases minhas). 
Para Saussure, assim como para Lévi-Strauss, a noção de sistema é fundamental para descrever de forma apropriada a dimensão dinâmica tanto dos fenômenos linguísticos como dos sociais. Em Saussure (1945:11): “O valor que consiste na solidariedade e na interdependência de uma significação com outra significação emana do sistema e implica na presença concreta do sistema em cada um de seus elementos". Os exemplos da utilização da noção de sistema para tornar mais clara a dimensão de fundamento epistemológico, tanto na linguística como no estruturalismo, são inúmeros, abundantes; neste sentido, acredita-se ser desnecessária uma demonstração mais farta ${ }^{18}$.

\section{A Fundamentação Sistêmica do Estrutural Funcionalismo}

Já na publicação de seu livro The Structure of Social Action ${ }^{19}$, em 1937, Talcott Parsons pretendia formular uma macroteoria, contrariamente ao mainstream da sociologia norte-americana, principalmente com relação à Escola de Chicago, voltando-se assim para os clássicos Europeus. Parsons, que chegou a se autodenominar um "teórico incurável" ${ }^{20}$, é bem caracterizado por Guy Rocher (1976:11) quando este afirma que toda a obra de Parsons "tem um único e mesmo objetivo: elaborar um quadro conceitual e teórico destinado a conferir à sociologia o status de ciência autêntica, relacionando-a logicamente com outras ciências humanas". Verifica-se, assim, como já mencionado, os dois grandes intentos de Parsons: a construção de uma teoria que atenda às necessidades de explicações gerais para o fenômeno social e que tenha um estatuto de cientificidade ao estilo das demais ciências.

Em La Estructura de la Acción Social (1968b) ${ }^{21}$, logo na Introdução, é possível observar o desejo de Parsons, por vezes explícito, por outras implícito de dar dinâmica, em termos de abordagem sistêmica, à ação social ou mesmo à estrutura social. No prefácio que elabora para a primeira edição, de 1937, Parsons parece evitar falar em dimensão sistêmica ou estrutural; entretanto, na segunda edição dessa mesma obra, 12 anos mais tarde, publicada em março de 1949, Parsons (1968b:22) diz que: "La Estructura de la Acción Social buscou ser uma contribuição à ciência social sistemática e não à história da ciência (ou seja, história do pensamento social)". Mais adiante, acrescenta: "Em muitos pontos, pelo menos, o deslocamento do nível teórico, a partir da análise da estrutura da ação social como tal, até a análise estrutural-funcional de sistemas sociais parece tornar possível uma importante série de esfor- 
ços nessa direção. Os sistemas sociais são, assim, 'em último termo', sistema de ação social" (Parsons, 1968:25)²2.

É importante observar-se que nesse período de 12 anos, Parsons já está incorporando mais claramente a noção de "estrutura" que, como foi visto, era cara à sociologia europeia - seu ponto de partida teórico -, mas associando às noções de "estrutura" e "estrutural" as também importantes noções à época de "funcional" e "funcionalismo". Entretanto, Parsons permanece com a noção de sistema e pouco a pouco a utiliza de forma cada vez mais consistente. Ele parece estar convicto de que, na sociologia, o uso da noção de sistema é o que de fato dá caráter de cientificidade à disciplina. A este respeito, Rocher (1976:17) argumenta que: "Se há algo que Parsons esteja convencido é de que as ciências humanas não podem ser científicas senão na medida em que recorram à análise sistêmica, como o fizeram as ciências físicas e, mais recentemente, a biologia". Na introdução de sua mais importante obra e também a mais lida na Europa de um sociólogo norte-americano, El Sistema Social, publicada em 1951, o próprio Parsons afirma que o título da mesma "obedece fundamentalmente à insistência do professor L. J. Henderson na importância extremada do conceito de sistema na teoria científica e em sua clara compreensão de que o intento de delimitar o sistema social como um sistema constitui a contribuição mais importante da grande obra de Pareto" (1966:17; ênfases minhas) ${ }^{23}$.

Parsons $(1966 ; 1968)$, quando da publicação de The Social System, já estava convicto da necessidade da análise sistêmica para a apreensão dos fenômenos de natureza social. É neste sentido que articula os elementos estruturais do sistema de ação, isto é, o sistema de ação que diz respeito à organização das relações de interações entre ator e situação ("os objetos sociais"); as variáveis que estruturam todo o sistema de ação e os pré-requisitos funcionais desse sistema. O Esquema 2 a seguir é composto de duas partes: a primeira, feita para este artigo; e a segunda, retirada de Rocher (1976:53), ilustra a ideia de dinâmica que Parsons pretendeu dar ao seu modelo teórico.

Parsons $(1966 ; 1968)$ necessitou da noção de sistema para dar a dinâmica necessária à sua teoria da sociologia. Os conceitos de estrutura e de função não seriam suficientes para denotar a dinâmica necessária por ele identificada nos fenômenos sociais contemporâneos. Nesse aspecto, é interessante notar que este autor foi um dos pioneiros, na teoria social, a buscar a articulação entre ação e estrutura que, na Europa, só ocorreu 
Esquema 2

Sistema de Ação em Parsons

(primeira parte)

\section{Sistema de Ação em Parsons}

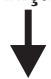

Sistema como um substrato de fundamentação teórica; por este motivo, visto como um sistema cuja estrutura apresenta um nível de retroalimentação, no sentido proposto pela Cibernética, e certas condições específicas para o seu funcionamento.

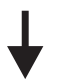

O sistema de ação, dada a sua complexidade, exige três condições

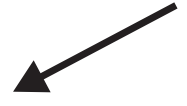

1. Condição de Estrutura

Modalidade de organização que apresente elementos ou componentes relativamente estáveis.

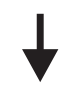

2. Noção de Função

Para que o sistema exista e se mantenha, certas necessidades devem ser satisfeitas: pré-requisitos funcionais ou dimensão funcional do sistema.

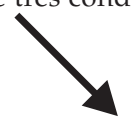

3. Refere-se a ele mesmo (autoretroalimentação)

O sistema é que deve estabelecer certas regras e normas na sua própria sistematicidade.

\section{Estrutura do Sistema Geral de Ação Pré-Requisitos Funcionais ou Paradigma Funcional do Sistema de Ação (segunda parte)}

A

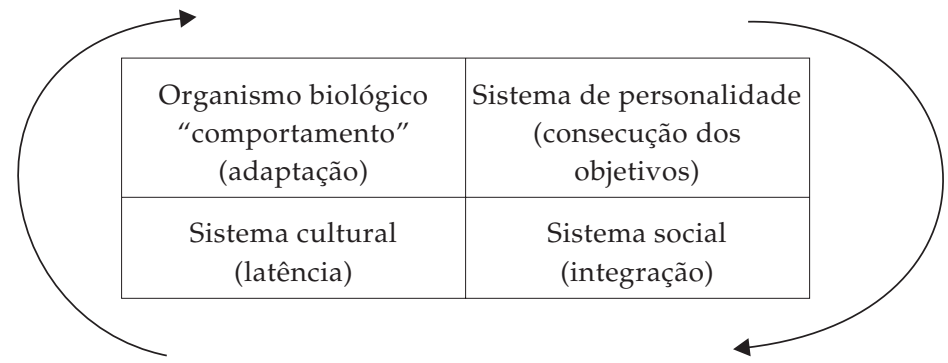

Obs.: Este já famoso esquema (Roger, 1976:53) representa a dimensão sistêmica e a dinamicidade existente entre o seu sistema biológico, seu sistema de personalidade, sistema social e sistema cultural. [As setas que dão ideia de movimento não constam no original.]

após a crise do estruturalismo propriamente dito. É relativamente comum na literatura teórica de sociologia defrontar-se com o fato de que os esforços para a integração da ação (subjetivista) e da estrutura (objetivista) no mesmo escopo explicativo têm sido feitos pelo pós-estruturalismo - movimento este assim denominado por pensadores nor- 
te-americanos, após a crise do estruturalismo, para etiquetarem de um modo geral todos os esforços teóricos que surgiram, sobretudo na Europa, a partir dos anos 1970. Entretanto, raramente é mencionado que tal esforço da sociologia contemporânea já se encontrava na teoria parsoniana, no início da década de 1950, com sua obra The Social System.

A articulação teórica entre ação e estrutura, desenvolvida por Parsons foi fortemente influenciada pela cibernética durante os anos 1940 e, como comentado anteriormente, essa nova disciplina estava obtendo importantes avanços teóricos e empíricos em diferentes áreas do conhecimento científico, cujo conceito de sistema assume uma dimensão central. Sem sistema, por exemplo, dificilmente haveria cibernética, ciência da comunicação ou ciência da cognição. Parsons utiliza esses fundamentos para integrar as dimensões funcionais do sistema de ação; dos subsistemas de sistema de ação, numa relação de hierarquia cibernética, conforme o ilustra o Esquema 3.

Esquema 3

Hierarquia Cibernética do Sistema Geral de Ação

\begin{tabular}{|c|c|c|c|}
\hline $\begin{array}{c}\text { Dimensões Funcionais } \\
\text { do Sistema de Ação } \\
\text { Funções Primárias }\end{array}$ & $\begin{array}{l}\text { Subsistemas do } \\
\text { Sistema de Ação }\end{array}$ & \multicolumn{2}{|c|}{ Relações Cibernéticas } \\
\hline Latência & Sistema cultural & \multicolumn{2}{|c|}{$\begin{array}{l}\text { Rico em informação } \\
\text { (controles) }\end{array}$} \\
\hline Integração & Sistema social & $\begin{array}{l}\text { Hierarquia } \\
\text { dos fatores de } \\
\text { condiciona- } \\
\text { mento }\end{array}$ & $\begin{array}{l}\text { Hierarquia } \\
\text { dos fatores } \\
\text { dos fatores de } \\
\text { controle }\end{array}$ \\
\hline $\begin{array}{l}\text { Consecução dos } \\
\text { objetivos }\end{array}$ & $\begin{array}{l}\text { Sistema psíquico ou } \\
\text { de personalidade }\end{array}$ & & \\
\hline Adaptação & Sistema orgânico & Rico em energi & \\
\hline
\end{tabular}

Fonte: Rocher (1976:58).

No esquema anterior, é possível observar que subsistema orgânico é o mais rico em energia (movimento) e, ao mesmo tempo, o mais pobre em informação (não possui a "totalidade" da informação de uma sociedade). Assim, vai acontecendo com o subsistema de personalidade e com 
subsistema social, até que se chegue ao subsistema cultural. Esse, seguindo o esquema cibernético, é mais rico em informação (possui a totalidade da informação de uma sociedade) e mais desprovido de energia, movimento (é mais estático, não muda facilmente). Entre estes quatro subsistemas estabelece-se, portanto, uma hierarquia de controles que se exercem sobre o subsistema social, que, por sua vez, se exerce sobre o subsistema de personalidade, que se exerce sobre o subsistema orgânico, numa dinâmica circular e retroalimentativa (Parsons, 1966, 1968; Rocher, 1976).

O que se deseja salientar é que o pensamento teórico parsoniano de fato está organizado sobre uma plataforma cuja fundamentação é sistêmi$c a$. As dimensões estruturais são dimensões da própria sistematização (formação) do sistema; a dimensão funcional é uma dimensão que fica atrelada ao sistema social no que se refere ao "tipo", isto é, à especificidade de cada sistema: político, econômico, social etc. Em outras palavras, a noção estrutural na teoria de Parsons diz respeito à formação e à "dimensão" do próprio sistema, ao passo que a noção de função quase nada inova no sentido da utilização do termo pela tradição sociológica. A inovação teórica proposta por Parsons de fato está na utilização da noção de sistema no sentido de sua mobilidade cibernética, como ciência do controle e da informação. Em outro lugar salientou-se que:

Ao analisarmos, a partir de uma perspectiva sociológica do conhecimento científico a incorporação do conceito de sistema nos estudos propostos por Parsons, (...) verificamos que ela se coloca à meia distância entre, de um lado, a forte noção de função e de estrutura predominante na teoria sociológica clássica e, de outro lado, que Parsons está absorvendo as inovações que estão sendo desenvolvidas no âmbito da reflexão sistêmica pela Cibernética e pela Biologia, quase que genuinamente americanas. Isso explica o constante uso da noção de estrutura e de sistema, às vezes como sinônimos, às vezes como conceitos que possibilitam alternar a idéia de estática e dinâmica do fenômeno social. (...) Essa ambiguidade conceitual (...) no momento em que Parsons está elaborando o seu "Social System" é justamente um momento de profundas transformações no escopo geral do conhecimento científico, quer seja na Biologia, na Psicologia, e mesmo na Sociologia. (...) As novas noções sistêmicas que estavam sendo importadas para o interior da teoria sociológica não tinham mais que poucos anos. A data de nascimento da própria Cibernética, com a publicação de artigos que efetivamente trazem a noção de controle informacional, através de uma circularidade operativa de um sistema (...) foi em 1943 (Rodrigues, 2003:295-296). 
No estruturalismo, o termo adotado continuou sendo "estrutura", como se buscou demonstrar anteriormente. Não porque os termos estrutura e estruturalismo explicassem melhor o fundamento epistemológico proposto por Saussure e que foi transposto na sua íntegra para o estudo dos fenômenos sociais por Lévi-Strauss, mas sim porque o termo estrutura estava mais em voga no estudo da sociologia, como já comentado. Mesmo porque o termo sistema, sem dúvida, melhor reflete a dimensão relacional dos elementos presentes no sistema linguístico e que determinam o entendimento no momento da fala. O mesmo pode ser pensado para os sistemas sociais, em que os elementos subjacentes às diferentes práticas sociais, em correlação dinâmica uns com os outros, "sobredeterminam" as diferentes manifestações de grupos sociais.

Quando se apresentou neste artigo o Esquema 1, o intento era o de justamente demonstrar que as duas vertentes teóricas sociológicas - o pensamento sistêmico norte-americano e, concomitantemente, o desenvolvimento do estruturalismo francês - repousavam sobre um mesmo fundamento (ou plataforma) epistemológico sistêmico. Em outros termos, a teoria social contemporânea necessitava de uma base de fundamentação que lhe desse mobilidade, refletindo as próprias mudanças da realidade social. Ora, dentre outras características que a noção de sistema apresentou durante todo o século XX, foi a ideia de dinâmica. Dos escassos trabalhos teóricos que se reportam às características dessas duas abordagens sociológicas é a obra de um dos maiores estudiosos da atualidade dos conceitos de sistema e de estrutura, Mario G. Losano que afirma:

O mérito que não poderá jamais ser negado ao estruturalismo consiste em ele ter aberto a Europa à teoria dos sistemas: O núcleo da mensagem, oculto mas vital, do estruturalismo é uma orientação conceitual que encontra explícita expressão na análise sistêmica. Ou seja, o estruturalismo é a teoria que rompe com a antiga concepção europeia do sistema externo ou descritivo e que propõe uma noção moderna dele (2011:229-30; ênfases minhas).

Comunga-se desse mesmo ponto de vista de Losano. Estas duas vertentes se interfecundaram de modo importante, significativo para a teoria contemporânea, aquela que se desenvolveu a partir do final da década de 1970 e início da de 1980 até os dias de hoje, mas o fizeram de modo "discreto", silencioso, como dois "rivais elegantes". As teorias norte-americanas, mas, principalmente, as europeias que se seguiram 
após a crise do estruturalismo, têm se fundado, em sua maioria, em uma perspectiva sistêmica - considerando os avanços epistemológicos deste conceito, umas mais, outras menos. Fato é que a chamada matriz pós-estruturalista (nos termos que estamos empregando aqui, isto é, que busca a articulação entre estrutura e ação) tem se constituído em boa medida em uma plataforma sistêmica, tal como, por exemplo: Giddens (1989); Laclau e Mouffe (2011); Laclau (2005); Luhmann $(2007,1998)$.

\section{UMA "REVOLUÇÃO CIENTÍFICA" ÀS AVESSAS OU CONSOLIDAÇÃO DO PARADIGMA SISTÊMICO?}

A forma de desenvolvimento não linear da ciência, proposta por Thomas Khun (1996), não se mostrou eficiente apenas para desconstruir o mito do linear progresso da ciência que sempre avançava, baseada em um método universal e quase infalível, oriundo da chamada received view ${ }^{24}$, perspectiva esta que perdurou durante praticamente toda a primeira metade do século XX. A partir da sua obra A Estrutura das Revoluções Científicas, desde o seu aparecimento em 1962, muito tem sido dito sobre paradigmas nas ciências de uma forma geral. Quando se fala em "mudança de paradigma", no sentido proposto por Kuhn - mesmo considerando suas obras posteriores $(1979,2006,2011)$ - ou em sentidos similares, como "estilo de raciocínio", proposto por Ian Hacking (2012), certamente se está falando na busca de caminhos outros, ou "outro", no sentido de alter. Entretanto, a dificuldade está no fato de que caminhos alternativos, em se tratando da produção do conhecimento científico, sempre se referem às questões de fundamento e, consequentemente, epistemológicas e de método.

Apesar de Thomas Kuhn ter demonstrado algumas das mudanças de paradigma na produção do conhecimento científico nas hard sciences ${ }^{25}$, têm sido os cientistas sociais - sobretudo aqueles que trabalham com science studies ou teoria social - que, com certa frequência, utilizam esta noção. Entretanto, o fazem, quase sempre, de forma indicativa ou prescritiva - quando se referem à necessidade de reformulação paradigmática, dada a crescente complexidade da realidade social -, e nunca de forma demonstrativa, isto é, apontando uma efetiva ruptura com os parâmetros de produção da "ciência normal". Certamente existe uma clara dificuldade de ruptura ou de demonstração de rupturas que tem havido no decorrer da produção de conhecimento científico nas ciências sociais. É compreensível que as descontinuidades de fundamentação 
teórico-epistemológicas e, consequentemente, de método, não sejam percebidas no mesmo momento em que estão sendo operadas. É necessário o distanciamento temporal e, por conseguinte, a crítica e o debate científico para que tais mudanças sejam efetivamente percebidas e avaliadas como tal, independentemente de quão profundas sejam.

É a historicização reflexiva de uma determinada área do conhecimento, ou mesmo de uma disciplina, que faz com que se perceba não apenas as revoluções científicas - estas parecem que, com o avanço da pesquisa nos dias de hoje, têm se tornado cada vez mais raras -, mas inclusive as pequenas descontinuidades, mudanças de rumo, ou mesmo de agenda de "programas de pesquisa", nos termos de Imre Lakatos (1993). Entretanto, a reflexão histórica do desenvolvimento epistemológico, teórico e empírico de um determinado conhecimento disciplinar também pode apontar não somente rupturas, revoluções, crises da ciência normal, como também processos de fundamentação teórico-epistemológicos da investigação científica que são contrários às ideias de dissolução, descontinuidade, supressão, ou mesmo de crise de um determinado paradigma científico, em detrimento de outro que emerge. É possível a identificação de processos de sínteses paradigmáticas, de aglutinação, de continuidade, culminando no fortalecimento de um determinado paradigma.

Isto foi o que aconteceu com o conceito de sistema, que de conceito passou a ser usado de forma mais ampla, como noção sistêmica; abordagem sistêmica; pensamento sistêmico, assumindo, inclusive, o status de teoria sistêmica, independentemente da adjetivação que lhe seja colocada sociológica, política, econômica, biológica etc. Os avanços epistemológicos obtidos pelo "conceito" de sistema, desde (e mesmo anteriormente) a célebre obra de Ludwig Von Bertalanffy (2008), a Teoria Geral dos Sistemas, publicada pela primeira vez (tardiamente) em 1968 - muitas de suas reflexões teóricas já haviam sido publicadas em periódicos especializados -, passaram a constituir um espaço de debate, por nós denominado plataforma cognitiva que, como categoria epistemológica, permite comportar e dar sentido à complexa dinâmica de avanços, de transformações e mesmo de ressemantizações teórico-conceituais, como no caso das reflexões sistêmicas.

Não faz parte da pauta deste artigo discutir de modo mais pormenorizado os avanços que a teoria sistêmica obteve em diferentes áreas do conhecimento, também com reflexos importantes nas ciências sociais. 
O que se deseja destacar é o fato de que, no caso dos avanços epistemológicos sistêmicos, contrariamente à noção de revolução científica, a "sistêmica" - mesmo considerando seus "giros" epistemológicos e de fundamentação (revoluções?) -, tem revelado continuidades, convergências que, de forma "silenciosa", têm permitido a tecelagem do processo de sinteses (inclusive disciplinares), robustecendo um paradigma: o paradigma sistêmico. Talvez seja possível falar em uma espécie de "revolução científica" ainda nos termos de Kuhn, porém às avessas: por mais que se busque suplantar um determinado conceito (ou paradigma), tudo o que se faz - como uma espécie de efeito colateral - é reforçá-lo, reafirmá-lo, fazendo com que, dentro de diferentes campos disciplinares específicos, ele (o conceito, o paradigma) se torne uma espécie de plataforma $\operatorname{cognitiv} a^{26}$ de onde se erige boa parte, não apenas da reflexão teórica, mas da sua efetiva proposição como modelos (teorias) para a explicação das diferentes dimensões da ciência.

(Recebido para publicação em agosto de 2013) (Aprovado para publicação em abril de 2014) 


\section{NOTAS}

1. Sobre o tema ver Cuin e Gresle (1994); Levine (1997).

2. Para que se tenha uma percepção mais precisa da Escola de Chicago em termos de sua pesquisa empírica, é importante destacar este trecho escrito por Levine (1997:234): “O desafio apresentado pela síntese pragmatista para uma ciência da sociologia foi triplo. A sociologia precisava desenvolver uma concepção de fenômenos sociais que caracterizasse os processos mentais subjetivos de agentes, mas entendesse tais processos subjetivos como efeitos e causas de processos sociais. (...) Essas tarefas foram abordadas com extraordinária criatividade por Charles Horton Cooley, William I. Thomas e Robert Ezra Park".

3. Sob a etiqueta "sistêmica" os teóricos americanos, à época, colocavam uma grande variedade de esforços teóricos para explicar o fenômeno social, com diferentes dimensões empíricas e variadas bases epistemológica.

4. Florian Znaniechi, em parceria com William I. Thomas, publicou o conhecido trabalho intitulado The Polish Peasant in Europe and America; Pitirim Sorokin publicou dois importantes volumes sobre a sociologia norte-americana: Contemporary Sociological Theories, em 1928 (a edição por nós utilizada está em língua espanhola e é de 1951), e Sociological Theories of Today, em 1969 (a edição por nós utilizada está em português e é de 1971). Para um aprofundamento sobre a sociologia estadunidense, ver também Gurvitch e Moore (1970, v.1).

5. Para um maior conhecimento do debate, ver: Gurvitch e Moore (1970:vol. 1 e vol. 2); Levine (1997); Cuin e Gresle (1994).

6. Conforme mencionamos anteriormente, a abordagem sistêmica já era objeto de discussão na sociologia americana. Entretanto, essa abordagem ganha consistência a partir de Parsons, sobretudo em seus ensaios da década de 1940. Para um aprofundamento dessa discussão, ver: Gouldner (1979); Parsons et al. (1961); Sorokin (1951; 1971). Há de se ter cuidado para não confundir a sociologia estrutural que de certa forma fazia parte da reflexão sociológica clássica, tendo sido o termo utilizado por Marx, Durkheim, Radcliffe-Brown etc., com o termo estruturalismo, desenvolvido pelo dinamarquês Louis Hjelmslev, em 1939 (Dosse, 1993; Rodrigues, 2006).

7. Trata-se das conferências que aconteceram na Fundação Josiah Macy Jr., entre os anos de 1946 e 1953, em Nova York, com os mais renomados cientistas de diferentes áreas do conhecimento. "O sociólogo Paul Lazarsfeld participou, como convidado, do primeiro encontro das famosas reuniões promovidas pela Fundação Macy, realizado em Nova York, em março de 1946. Em setembro do mesmo ano, também a convite de Norbert Wiener e von Neumann, Parsons e Merton participaram da conferência que se chamou 'Teleological Mechanisms in Society' e em outubro do mesmo ano participaram da conferência dirigida por McCulloch e denominada 'Teleological Mechanisms and Circular Causal Systems'" (Rodrigues, 2003:294).

8. As datas são esforços didáticos de maior aproximação possível. Com relação ao estruturalismo, por exemplo, salienta-se que uma das obras paradigmáticas desse movimento, a Antropologia Estrutural, foi publicada em 1958. Entretanto, esta foi fruto da reunião de artigos escritos entre 1940 e 1950, segundo o próprio autor (Lévi-Strauss, 2003; Rodrigues, 2010). 
9. Para um maior aprofundamento desta discussão, ver Parsons (1968a); Rocher (1976); Rodrigues e Mendonça (2006); Rodrigues e Neves (2012); Rodrigues (2013).

10. Conforme Dosse (1993:33), foi Jakobson quem aconselhou Lévi-Strauss a "começar a redigir, em 1943, a sua tese que se converterá em obra essencial: Les Structures Élémentaires de la Parente.

11. A este respeito, Losano (2011:230-231) é muito enfático: “O estruturalismo também reagiu ao empirismo da primeira metade do século $X X$, mas ao mesmo tempo não foi um movimento puramente filosófico (como, por exemplo, o existencialismo) e pode, portanto, apresentar-se também como uma alternativa ao marxismo mais ortodoxo".

12. Sobre este tema, ver: Blau (1977); Gurvitch e Moore (1970); Merton (1970); Rex (1973).

13. Para Saint-Sernin (1998:89), por exemplo, "A estrutura é uma característica das coisas, enquanto o estruturalismo é uma concepção que pretende explicar a origem, a forma e a diversidade das estruturas encontrada na natureza e na sociedade".

14. Entre os bons exemplos da perspectiva estrutural que continua, principalmente nos Estados Unidos, está o clássico livro de Robert K. Merton, Social Theory and Social Structure, publicado pela primeira vez em 1949 (para este artigo estamos utilizando a edição brasileira de 1970) e também a coletânea, com a participação de diversos teóricos norte-americanos, organizada por Peter M. Blau, intitulada Approaches to the Study of Social Structure, publicada em 1975 (para este artigo estamos utilizando a edição brasileira, cujo título é Introdução ao Estudo da Estrutura Social, publicada em 1977). Pouco a pouco a discussão "estrutural" vai perdendo força e dando lugar, nos Estados Unidos, para a discussão sistêmica e, na Europa, particularmente na França, para o "estruturalismo francês".

15. Recomenda-se, principalmente, as seguintes obras: Dosse (1993: vols. 1 e 2); Bastide (1971); Coelho (1968); Lepargneur (1972); Pouillon (1968).

16. Sabe-se que a obra Cours de Linguistique Générale resultou da compilação de notas de suas aulas realizada por dois de seus alunos e discípulos: Charles Bally e Albert Sechehaye, com a colaboração de Albert Reidlinger (Carvalho, 1980).

17. Esta passagem é uma citação de Benveniste, a qual faz parte da Introdução de Os Pensadores: Textos Selecionados de Ferdinand de Saussure, Roman Jakobson, Louis TrØlle Hjelmslev e Noam Chomsky (1978:VII).

18. Não se poderia deixar de chamar a atenção para uma discussão neste mesmo sentido que foi feita em outro lugar por este autor: "As noções de estrutura e de sistema têm sido utilizadas, muitas vezes, principalmente até o início dos anos 70, recém passados, de forma sinônima. Não raramente, a noção de sistema é utilizada nos textos estruturalistas para reforçar, complementar e até mesmo explicar o próprio conceito de estrutura. Piaget, por exemplo, em O Estruturalismo, no item das definições, argumenta: "Em uma primeira aproximação, uma estrutura é um sistema de transformações que comporta leis enquanto sistemas..." (1979:8). Bastide, em sua introdução que visa mostrar as diferentes acepções do termo estrutura, diz: "A noção de estrutura poderia, então, ser assim definida: sistema integrado, de modo que a mudança produzida num elemento provoca uma mudança nos outros elementos [...] Mas esse sistema (o que distingue da organização) está 'latente' nos objetos"' (Bastide apud Rodrigues, 2006:35; ênfases do original).

19. Neste artigo, estamos utilizando a edição em língua espanhola (Parsons, 1966). 


\section{Léo Peixoto Rodrigues}

20. Termo mencionado pelo próprio Parsons na dedicatória que fez a sua esposa, por ocasião da publicação de The Social System, em 1951. Em inglês: “(...) an incurable theorist" (Parsons, 1968a).

21. A passagem a seguir, apresentada por Guy Rocher, bem resume o intento parsoniano: "Foi assim que Talcott Parsons redigiu seu primeiro grande trabalho The Structure of Social Action, que apareceu em 1937 e que devia rapidamente consagrar sua reputação como teórico. Neste alentado estudo Parsons reagrupou as análises de Marshall, Weber e Durkheim, perseguindo concorrentemente três objetivos bastante diferentes. Tentava primeiro fazer o confronto das explicações dadas por cada um deles sobre o capitalismo moderno (...) comparar a maneira pela qual Pareto, Weber e Durkheim resolvem o problema das relações entre econômico e social com a solução adotada por Marshall (...) salientar a 'convergência' implícita no pensamento destes para aquilo que Parsons chamava de "teoria voluntarista da ação'" (1976:17).

22. Todas as traduções foram feitas livremente para utilização neste artigo.

23. Para um conhecimento mais detalhado da relação entre L. J. Henderson, a obra de Pareto e de Parsons, no que se refere ao pensamento sistêmico, ver Rodrigues (2013).

24. O termo received view, em português geralmente traduzido como "concepção herdada", surgiu logo após o contexto da publicação de A Estrutura das Revoluções Científicas. Putnam, um dos principais críticos do positivismo, denominou essa corrente de pensamento analítico, que havia se ampliado e se enriquecido sob a interação com diversas linhas de pensamento. $\mathrm{O}$ termo passou a ser utilizado para caracterizar uma perspectiva sobre a ciência em que ela se apresentava como se fosse imune ao contexto social; compreendida como autossuficiente e autoexplicativa; praticamente blindada com relação ao meio (social, cultural, político e econômico) no qual realizava a sua atividade de "gerar" conhecimento.

25. Em A Estrutura das Revoluções Científicas, Khun faz alusão às “descobertas" do oxigênio, dos raios X e da Garrafa de Leyden, afirmando que todas estas descobertas "causaram mudanças de paradigma ou contribuíram para tanto" (1996:93).

26. A proposta do uso do termo "plataforma cognitiva" tem a intenção inicial de desviar da atual discussão sobre fundacionismo e o pós-fundacionismo que se coloca numa "disputa" metafísica, no sentido anunciado (ou denunciado) com muita propriedade por Derrida, em que argumenta que "a história da metafísica, tal como a história do ocidente, seria a história dessas metáforas e metonímias. A forma matriarcal seria a determinação do ser como presença em todos os sentidos da palavra. Poder-se-ia mostrar que todos os nomes do fundamento, do princípio ou do centro designaram sempre a invariante de uma presença (eidos, archè, telos, energeia, ousia) (essência, existência, substância, sujeito) aletheia (transcendentalidade, consciência, Deus, homem etc.)" (1967:103; ênfases do original). Além disso, objetivou-se também o deslocamento de uma abordagem filosófica para uma abordagem da teoria da cognição; ou ainda, em termos noológicos, como bem descreve Mannheim: "atingimos um nível teórico ou noológico sempre que consideramos não apenas o conteúdo, mas igualmente a forma, a estrutura conceitual de um modo de pensamento..." (1982:83). Neste sentido, incluímos noções tais como: mecanicista, organicista, funcionalista, estruturalista, sistêmico etc. 


\section{Platô Sistêmico na Teoria Social}

\section{REFERÊNCIAS BIBLIOGRÁFICAS}

BASTIDE, Roger (org.). (1971), Os Usos e Sentidos do Termo Estrutura. São Paulo, Editora Herder.

BERTALANFFY, Ludwig von. (2008), Teoría General de los Sistemas. México, Fondo de Cultura Económica.

BLAU, Piter (org.). (1977), Introdução ao Estudo da Estrutura Social. Rio de Janeiro, Zahar.

CARVALHO, Castelar de. (1980), Para Compreender Saussure. Rio de Janeiro, Editora Rio.

COELHO, Eduardo P. (org.). (1968), Estruturalismo: Antologia de Textos Teóricos. São Paulo, Martins Fontes.

CUIN, Charles-Henry e GRESLE, François. (1994), História da Sociologia. São Paulo, Ensaio.

DERRIDA, Jacques. (1967), “A Estrutura, o Signo e o Jogo no Discurso das Ciências Humanas", in E. Coelho, Estruturalismo: Antologia de Textos Teóricos. São Paulo, Martins Fontes.

DOSSE, François. (1993), História do Estruturalismo: O Campo do Signo, 1945/1966. São Paulo, Ensaio.

GIDDENS, Anthony. (1989), A Constituição da Sociedade. São Paulo, Martins Fontes. (2001), Em Defesa da Sociologia. São Paulo, Cultrix/Unesp.

GOULDNER, Alvin W. (1979), La Sociología Actual: Renovación y Crítica. Madrid, Alianza Editorial.

GURVITCH, George e MOORE, Wilbert (orgs.). (1970), Sociología del Siglo XX. Barcelona, El Ateneo, vols. 1 e 2.

HACKING, Ian. (2012), Representar e Intervir. Tópicos Introdutórios de Filosofia da Ciência Natural. Rio de Janeiro, UERJ.

HUISMAN, Denis. (2001), História do Existencialismo. Bauru, EDUSC.

KUHN, Thomas. (1979), "Lógica da Descoberta ou Psicologia da Pesquisa?" in I. Lakatos e A. Musgrave (orgs.), A Crítica e o Desenvolvimento do Conhecimento. São Paulo, Edusp.

. (1996), A Estrutura das Revoluções Científicas. São Paulo, Perspectiva.

(2006), O Caminho desde a Estrutura. São Paulo, Unesp.

. (2011), Tensão Essencial. São Paulo, Unesp.

LACLAU, Ernesto. (2005), La Razón Populista. Buenos Aires, Fondo de Cultura Económica. e MOUFFE, Chantal. (2011), Hegemonía y Estratégia Socialista: Hacia una Radicalización de la Democracia. Buenos Aires, Fondo de Cultura Económica.

LAKATOS, Imre. (1993), La Metodología de los Programas de Investigación Científica. Madrid, Alianza.

LEPARGNEUR, Hubert. (1972), Introdução aos Estruturalismos. São Paulo, Herder.

LEVINE, Donald. (1997), Visões da Tradição Sociológica. Rio de Janeiro, Zahar.

DADOS - Revista de Ciências Sociais, Rio de Janeiro, vol. 57, nº 4, 2014 


\section{Léo Peixoto Rodrigues}

LÉVI-STRAUSS, Claude. (2003), Antropologia Estrutural. Rio de Janeiro, Tempo Brasileiro.

LOSANO, Mario G. (2011), Sistema e Estrutura no Direito: Do Século XXà Pós-Modernidade. São Paulo, Martins Fontes, vol. 3.

LUHMANN, Niklas. (1998), Sistemas Sociales: Lineamientos para una Teoría General. Rudí (Barcelona), Anthropos; México, Universidade Iberoamericana; Santafé de Bogotá, CEJA, Pontifícia Universidad Javeriana.

. (2007), La Sociedad de la Sociedad. México, Iberoamericana/Herder.

MANNHEIM, Karl. (1982), Ideologia e Utopia. Rio de Janeiro, Zahar.

MERTON, Robert K. (1970), Sociologia: Teoria e Estrutura. São Paulo, Mestre Jou.

PARSONS, Talcott. (1966), El Sistema Social. Madrid, Revista de Ocidente.

(1968a), The Social System. New York, The Free Press.

(1968b), La Estructura de la Acción Social. Madrid, Guadarrama.

PARSONS, Talcott et al. (1961), Theories of Society: Foundation of Modern Sociological Theory. New York, The Free Press of Glencoe Inc.

PIAGET, Jean. (1979), O Estruturalismo. São Paulo, Difusão Européia do Livro.

POUILLON, Jean. (1968), “Uma Tentativa de Definição”, in E. P. Coelho (org.), Estruturalismo: Antologia de Textos Teóricos. São Paulo, Martins Fontes.

REX, John. (1973), Problemas Fundamentais da Teoria Sociológica. Rio de Janeiro, Zahar.

ROCHER, Guy. (1976), Talcott Parsons e a Sociologia Americana. Rio de Janeiro, Francisco Alves.

RODRIGUES, Léo P. (2003), As Teorias Sistêmicas de Vilfredo Pareto, Talcott Parsons e Niklas Luhmann (Re)visitadas pela Sociologia do Conhecimento Científico. Tese de Doutorado em Sociologia. Instituto de Filosofia e Ciências Humanas, Universidade Federal do Rio Grande do Sul, Porto Alegre.

. (2006), “A (Des)estruturação das Estruturas e a (Re)estruturação dos Sistemas: Uma Revisão Epistemológica Crítica", in L. P. Rodrigues e D. Mendonça (orgs.), Ernesto Laclau e Niklas Luhmann: Pós-fundacionismo, Abordagem Sistêmica e as Organizações Sociais. Porto Alegre, Ed. PUC-RS.

. (2010), "O Estruturalismo Francês: Aspectos Históricos e Epistemológicos", in R. Schulz (org.), Ensaios de Sociologia e Política. Pelotas, UFPel.

. (2013), “Da Fisiologia à Sociologia? Elementos para uma Revisão da História Teórica da Sociologia Sistêmica". Revista Brasileira de Ciências Sociais, vol. 28, no 82, pp. 165-178.

e MENDONÇA, Daniel de (orgs.). (2006), Ernesto Laclau e Niklas Luhmann: Pós-Fundacionalismo, Abordagens Sistêmicas e as Organizações Sociais. Porto Alegre, Ed. PUC-RS.

RODRIGUES, Léo P. e NEVES, Fabrício. (2012), Niklas Luhmann: A Sociedade como Sistema. Porto Alegre, Ed. PUC-RS.

SAINT-SERNIN, Bertrand. (1998), A Razão no Século XX. Rio de Janeiro, José Olympio; Brasília, Editora UnB. 
SAUSSURE, Ferdinand de. (1945), Curso de Lingüística General. Buenos Aires, Editorial Losada. et al. (1978), "Textos Escolhidos", in Os Pensadores. São Paulo, Abril Cultural, p. VII. SOROKIN, Pitirim. (1951), Teorías Sociológicas Contemporáneas. Buenos Aires, Depalma. . (1971), Novas Teorias Sociológicas. São Paulo, Globo/Unesp.

TIMASHEFF, Nicholas. (1971), Teoria Sociológica. Rio de Janeiro, Zahar. 


\section{Léo Peixoto Rodrigues}

\section{RESUMO}

Platô Sistêmico na Teoria Social: Uma Revolução Científica às Avessas

Este artigo objetiva confrontar duas vertentes teóricas que se desenvolveram concomitantemente em lados distintos do Atlântico: o estrutural-funcionalismo, nos Estados Unidos; e o estruturalismo na França. Ao analisar o conteúdo da história "oficial" da teoria sociológica este texto destaca que a noção de sistema não apenas dá a ambas as correntes teóricas um mesmo fundamento epistemológico, como também tal fato tem sido negligenciado pela história teórica da sociologia. Num segundo momento, argumenta-se que a perspectiva sistêmica, desde então - e mesmo antes - constituiu-se durante o século XX, até os dias de hoje, como um paradigma que se robustece, provocando uma "revolução científica" (nos termos propostos por Thomas Kuhn), às avessas. Através de diferentes processos de sínteses, a teoria sistêmica tem se fortalecido como possibilidade de fundamentação teórica e empírica, na produção sociológica europeia.

Palavras-chave: teoria social; teoria sistêmica; história das ciências sociais; epistemologia

\section{ABSTRACT \\ A Systemic Plateau in Social Theory: Scientific Revolution Inside-Out}

This article aims to confront two theoretical strands that evolved at the same time yet on opposite sides of the Atlantic: structural functionalism in the United States, and structuralism in France. By analyzing the "official" history of sociological theory, this article argues that the notion of a system confers both strands not only the same epistemic foundation, but also the fact that this notion has been ignored by the history of sociological theory. Secondly, it is argued that the systemic approach has since then - and even before - from the twentieth century onwards consolidated as a robust paradigm, which provokes a "scientific revolution" (in the sense advanced by Thomas Kuhn) which unfolds from the inside-out. Through different processes of synthesis, the systemic theory has strengthened itself as a possibility of theoretical and empirical foundation in the production of European sociology.

Keywords: social theory; social systems theory; history of social sciences; epistemology 


\section{RÉSUMÉ}

Plateau Systémique dans la Théorie Sociale: Une Révolution Scientifique a l'Inverse

Cet article vise à comparer deux courants théoriques qui se sont développées simultanément sur les différents côtés de l'Atlantique: le fonctionnalisme structurel aux États-Unis; et le structuralisme en France. En analysant le contenu de l'histoire "officielle" de la théorie sociologique ce texte souligne que la notion de système non seulement donne aux deux courants théoriques le même fondement épistémologique, mais aussi que ce fait a été négligé par l'histoire théorique de la sociologie. En deuxième lieu, l'auteur soutient que ce point de vue systémique, depuis lors - et même avant-s'est constitué au cours du XXe siècle, et jusqu'à nos jours, comme un paradigme qui est renforcé, provoquant une "révolution scientifique" (dans les termes proposés par Thomas Kuhn), dans le sens inverse. A partir de différents procédés de synthèse, la théorie systémique a été renforcée comme une possibilité de fondement théorique et empirique dans la production sociologique européenne.

Mots-clés: théorie sociale; théorie systémique; histoire des sciences sociales; épistémologie

\section{RESUMEN \\ Plató Sistémico en la Teoría Social: Una Revolución Científica al Revés}

Este artículo tiene como objetivo confrontar dos vertientes teóricas que se desarrollan de forma simultánea en lados distintos del Atlántico: el estructural-funcionalismo en Estados Unidos y el estructuralismo en Francia. Tras analizar el contenido de la historia "oficial" de la teoría sociológica, este texto sugiere que la noción de sistema no sólo ofrece a ambas corrientes teóricas un mismo fundamento epistemológico, sino que, además, este hecho ha sido omitido por la historia teórica de la sociología. En un segundo momento, se argumenta que la perspectiva sistémica, desde entonces - e incluso antes - se constituyó, desde el siglo XX hasta los días actuales, como un paradigma que se robustece, provocando una "revolución científica" (en los términos propuestos por Thomas Kuhn) al revés. A través de diferentes procesos de síntesis, la teoría sistémica se ha fortalecido como posibilidad de fundamentación teórica y empírica en la producción sociológica europea.

Palabras clave: teoría social; teoría sistémica; historia de las ciencias sociales; epistemología 